\title{
PAPER
}

\section{Community based rehabilitation after severe traumatic brain injury: a randomised controlled trial}

\section{J Powell, J Heslin, R Greenwood}

See end of article for authors' affiliations

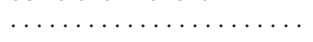

Correspondence to: Dr J Powell, Department of Psychology, Goldsmiths College, Lewisham Way, New Cross, London SEl 4 6NW, UK; i.powell@gold.ac.uk

Received 12 March 2001 In revised form 27 July 2001

Accepted 6 August 2001

\begin{abstract}
Objective: Evaluation of multidisciplinary community based outreach rehabilitation after severe traumatic brain injury (TBI).

Methods: A randomised controlled trial compared outreach treatment (mean of two sessions a week for 27.3 (SD 19.1) weeks) in community settings such as participants' homes, day centres, or workplaces, with provision of written information detailing alternative resources. Follow up for an average of 24.8 months after initial allocation was by a blinded independent assessor. Participants were aged 16-65, had sustained severe TBI between 3 months and 20 years previously, and had no other neurological conditions. Of 110 initially allocated, 48 outreach and 46 information participants were successfully followed up. Primary outcome measures (Barthel index (BI) and the brain injury community rehabilitation outcome-39 (BICRO-39)) focused on levels of activity and participation. Secondary measures were the functional independence measure and the functional assessment measure (FIM+FAM) and, in a subgroup of 46 participants, the hospital anxiety and depression scale. Analyses were non-parametric.

Results: outreach participants were significantly more likely to show gains on the $\mathrm{BI}$ and the BICRO-39 total score and self organisation and psychological wellbeing subscales. There were likewise strong trends $(p<0.10)$ for BICRO personal care and mobility, and on the FIM+FAM for personal care and cognitive functions. Differential improvements were not seen for indices of socialising, productive employment, anxiety, or depression. Median changes on individual subscales were small, reflecting the diversity of the clinical population; however, $40 \%$ of outreach but only $20 \%$ of information participants made a clinically significant improvement of $2+$ points on at least one BICRO-39 scale. Time since injury was unrelated to the magnitude of gains.

Conclusions: This is the first RCT of multidisciplinary community rehabilitation after severe TBI, and suggests that even years after injury it can yield benefits which outlive the active treatment period.
\end{abstract}

D uring the past decade it has been increasingly recognised that after acute and early inpatient treatment and rehabilitation after traumatic brain injury (TBI) there is a need for community based programmes which focus directly on enabling the brain injured person to re-engage with life as fully as possible. ${ }^{1}$ In their absence, improvements achieved during inpatient treatment may have limited impact on what the patient actually does when he or she is left to cope at home. Recognising this, the trend in North America over the past few years has been increasingly to shorten inpatient rehabilitation while enhancing the provision of community based interventions..$^{23}$ However, until recently there has been no good evidence to confirm the effectiveness of this approach.

An exceptional opportunity to conduct randomised treatment trials of community rehabilitation programmes for patients after TBI arose in 1992, when the Department of Health funded the development of 10 "model" services for patients with TBI. ${ }^{4}$ As part of this initiative, Wade et al found significant benefits of postdischarge support in patients who had had mild or moderate TBI. The model developed at the Homerton Hospital, by contrast, focused on patients after severe TBI and used a multidisciplinary outreach team, led by a clinical neuropsychologist, to deliver individualised retraining programmes. As the service was new, it was possible ethically to offer it on a randomised basis.

Treatment programmes were highly individualised in intensity, duration, and forms of therapy, reflecting the diversity of impairments and psychosocial problems which determine the difficulties presented by people after TBI. It was therefore the overall framework for delivering rehabilitation rather than specific components which was evaluated. We hypothesised that participants randomised to outreach rehabilitation would, as a group, make greater gains on measures of independence in activities of daily living, social participation, and psychological wellbeing than would those receiving only information about other existing sources of potential help.

\section{METHODS}

\section{The outreach team service}

Based in the urban setting of east London, the multidisciplinary team comprised two occupational therapists, a physiotherapist, a speech and language therapist, a clinical psychologist, and (intermittently) a half time social worker; it was directed clinically by a clinical psychologist (JP). Programmes were individualised, with clients typically seen in their own homes or other community settings (day centres, colleges, workplaces) for 2-6 hours a week. A goal planning framework, "contractually organised goal setting", was developed within which long term goals valued by the client and their carers and considered amenable to intervention by the team were worked towards via a series of written contracts which specified interim and short term goals achieved over 6-12 weeks. ${ }^{6}$ These were agreed between client, carer, and

Abbreviations: TBI, traumatic brain injury; $\mathrm{BI}$, Barthel index; $\mathrm{BICRO}-39$, brain injury community rehabilitation outcome-39; $M G I$, maximum gain index; FIM+FAM, functional independence+assessment measure; PTA, post-traumatic amnesia; HADS, hospital anxiety and depression scale 
team, and provided the basis for reviews at which decisions were taken about subsequent contracts or temporary/ permanent cessation of treatment. After the initial assessment period, clients were seen twice weekly for an average of 27.3 (SD 19.1) weeks.

\section{Protocol}

Ethical approval was given by the East London and City Health Authority ethics committee.

\section{Participants}

All participants had sustained TBI, verified by hospital or general practitioner records; were aged between 16 and 65 years; had no concurrent neurological diagnoses; lived within about 1 hour's travel time of the hospital; and had long term treatment goals agreed within the team as being amenable in principle to intervention. These goals could vary from increased independence in basic self care activities to resuming former employment roles. Participants were not excluded on the basis of concurrent or premorbid psychiatric disorders or drug or alcohol use, as to do so would have rendered the sample grossly non-representative. There was no limit on duration since injury, as clinical experience suggests that patients who have received inpatient rehabilitation often fail to maintain or capitalise on the gains that they have made and might therefore be well able to benefit from late input. Severity of brain injury was at least moderate, as indexed either by a retrospective estimate of post-traumatic amnesia exceeding 24 hours or by other neurological evidence (for example, neurosurgical evacuation of intracranial haematomas, clear and persisting neurological signs such as hemiparesis or ataxia).

Participants could either be living in the community already, or could be referred at point of discharge from the inpatient neurological rehabilitation unit at the Homerton Hospital. The second group received assessment and limited treatment and support from the outreach team over 1 month immediately after their discharge. This was necessary because it was often not possible to determine until close to the date of discharge whether outreach rehabilitation would be appropriate for a given patient; under such circumstances if a patient had been randomised to the information group the inpatient team would have had insufficient time to make alternative discharge plans. Those for whom treatment goals were definable after about 2 weeks of assessment at home were then randomised either to continue receiving outreach input; those allocated to the information group were given advice and some limited assistance with pursuing referrals to outpatient services.

\section{Design}

Participants, and where possible their primary carers, were assessed initially by two therapists from the team to determine eligibility and to collect baseline measures of function (fig 1). The randomisation procedure was described; it was explained that either type of help (outreach or information) might or might not be helpful and that the purpose of the study was to evaluate both.

The information condition entailed a single visit at home from a team therapist who gave the patient a specially collated booklet which listed a wide range of local and national resources and highlighted those of particular relevance to his or her needs.

All participants in both groups were followed up between 18 and 40 months after allocation by a research worker $(\mathrm{JH})$ who was independent of the outreach team and was kept blind to participants' treatment allocations. She was previously unknown to the participants, and introduced the assessments by saying that her purpose was to find out what types of difficulty they were still having. In addition, the self report questionnaires (the brain injury community rehabilitation outcome-39 ( BICRO-39) and the hospital anxiety and

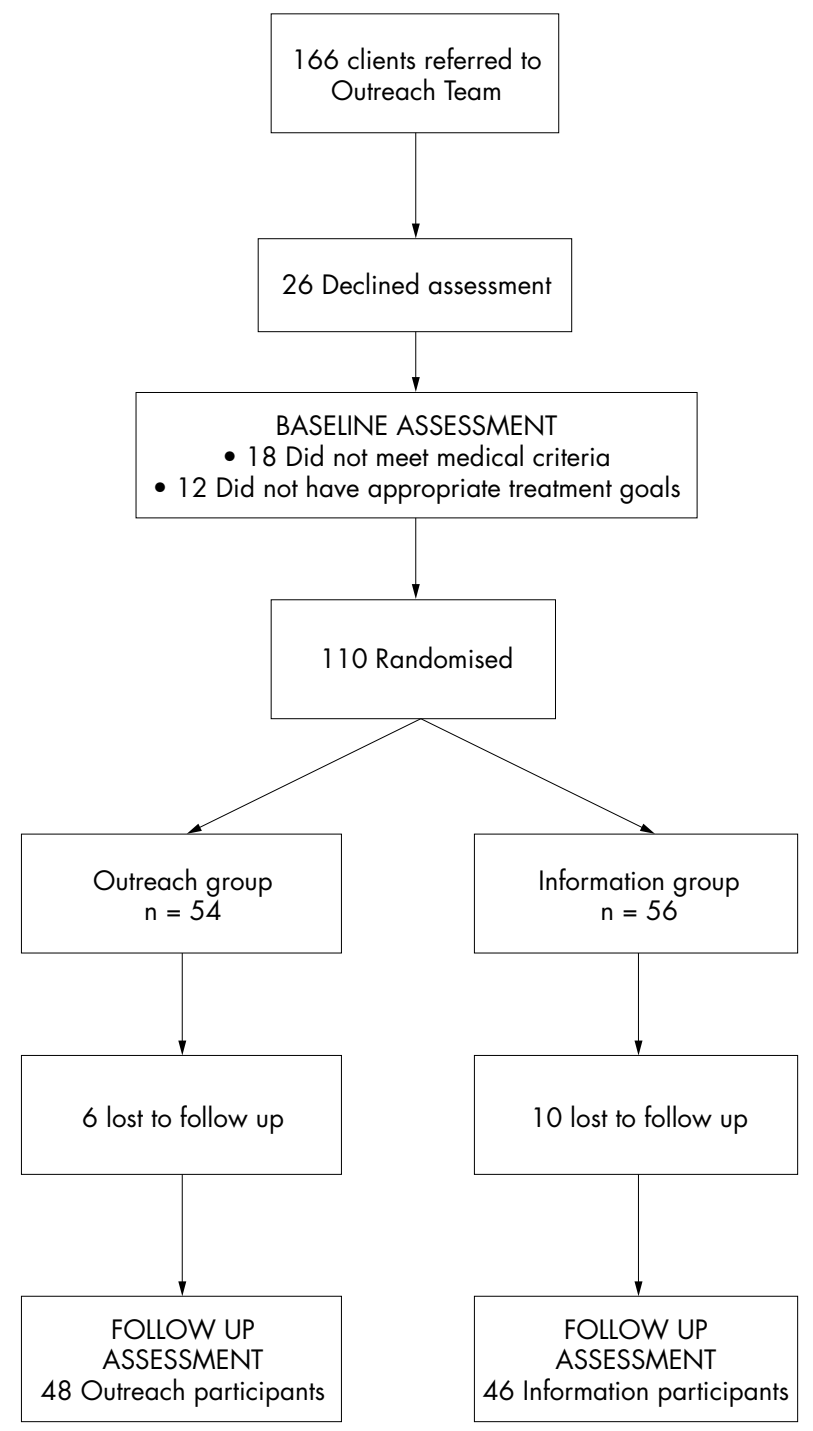

Figure 1 Diagram showing flow of participants through the study.

depression scale (HADS)) were completed by the participants, or their carers, or both without assistance from the assessor.

\section{Assignment}

Randomisation was conducted on an individual basis. Information/outreach codes (I and O) were written onto squares of paper, in equal proportion, and these were placed in a sealed, opaque envelope. This was prepared and held by the clinical director of the team. Once a participant's eligibility and agreement to participate had been established, one of the codes was drawn at random from the envelope by a therapist or other staff member who had not been involved in the patient's assessment, and it was then discarded and the envelope resealed.

\section{Blinding}

The study was single rather than double blind: given the nature of the programme under evaluation, neither participants nor therapists could be blinded to treatment condition. However, the independent follow up assessor was not informed of participants' allocation codes at any stage throughout data collection or data entry; the codes were entered only when the database was complete. She had no direct contact with the team and was physically based at a university some miles away from the hospital. Inevitably, however, some patients who had been treated by outreach, 
despite being instructed not to do so, inadvertently gave information during the interview assessment (for example, mentioning the names of their therapists) which disclosed their allocation. Thus although it is difficult to see how this could have been avoided, blinding was imperfect.

\section{Assessment measures}

Once a disabled person has returned to living in the community, critical outcomes relate to his or her participation in normal life roles including self care, domestic activities, social and leisure pursuits, education, and employment, and also to his or her psychological wellbeing and quality of life. Reengagement in these areas after brain injury is principally determined by residual cognitive and behavioural problems. ${ }^{7}$ Measures of functional ability such as the Barthel index (BI) ${ }^{8}$ and functional independence measure and functional assessment measure (FIM+FAM) ${ }^{9}$ capture only part of this information. At the start of this study, in 1992, there were no well validated measures sensitive to these dimensions of functioning after TBI, a difficulty that has subsequently been made explicit by Hall et al. ${ }^{10}$ Since then some have been published, at least three by participants in the Department of Health programme of which this study was part. ${ }^{11-13}$

The outcome measures used in this study are described below.

\section{Primary measures}

The unmodified Barthel index

The unmodified $\mathrm{BI}^{8}{ }^{14}{ }^{15}$ is an established measure of ability to undertake a range of basic activities of daily living (for example, grooming, toileting, mobilising) and is often considered to measure limitations in activity (disability). It has been less extensively studied after TBI than stroke but was recently found in an inpatient setting ${ }^{16}$ to be responsive to progress after brain injury. The maximum score of 20 indicates physical independence in basic self care activities and mobility. It was completed at baseline by the assessing therapists and at follow up by the research assessor based on a combination of limited observation and interview with the client and, if applicable, carers. Good agreement between qualified therapists and research assistants trained in administration of the BI has been established elsewhere. ${ }^{16}$

\section{The brain injury community rehabilitation outcome-39 scales}

The BICRO-39 scales ${ }^{12}$ measure levels of activity, participation, and psychological aspects of functioning in the community via ratings given by clients and by their carers. Validation data have been reported, ${ }^{12}$ and based on evidence of good patientcarer agreement, test-retest reliability, sensitivity to the effects of brain injury, and evidence of construct validity, the following six scales were selected for use here:

- Personal care: independence in basic self care activities (for example, using the toilet) and mobility/access to facilities within the home $(0=$ with no help to $5=$ can't do at all $)$.

- Mobility: independence in more physically demanding tasks ( for example, laundry, shopping; $0=$ with no help to $5=$ can't do at all).

- Self organisation: independence with structuring personal and domestic activities (for example, bill payments, managing appointments; $0=$ with no help to $5=$ can't do at all).

- Socialising: frequency of contact with people other than immediate family (for example, friends, colleagues; $0=$ never to $5=$ daily)

- Productive employment: frequency of engagement in education, work, or childcare $(0=$ not at all to $5=$ several hours a day).

- Psychological wellbeing: frequency of feeling impatient with self, bored, lonely, worn out, hopeless about the future, and angry with others $(0=$ never to $5=$ almost always $)$

Two subscales from the original version, tapping frequency of contact with family members (parents/sibs and partner/ own children) were not used here because, as noted in the validation study, the desirable direction of change in scores is likely to vary between patients depending on the level and nature of their contact on admission to a treatment service. There are clearly some brain injured patients whose high level of dependence on carers entails an intensity of contact with relatives which it is a priority to reduce; in other cases, alienation from family members is a problem. The same is not true of the other scale tapping social interactions-socialising: here, the contacts are with people outside the immediate household whom the patient is likely to see primarily through external work related or leisure activities, or intermittently through arranged visits.

One version of the questionnaire was completed by patients who were able to do so without assistance, and another version was completed on their behalf by a primary carer (where applicable). As there is evidence of high patient-carer agreement, ${ }^{12}$ if both forms were completed then mean scores were used.

As the BICRO-39 was under development in the early stages of this trial, baseline data were unavailable for some participants. Analyses are therefore based on 35 outreach and 40 information participants who had completed questionnaires at both intake and follow up. There was a small amount of missing data for some of the subscales as some participants omitted to complete a few questions.

BICRO scale scores are non-normally distributed, reflecting the heterogeneity of the client population: thus in each individual domain, only a subgroup of clients show difficulties at intake, whereas few clients show difficulties across all domains of functioning. When using the scales to index change over time (by subtracting follow up score from intake score) in the individual case, the magnitude and patterning of change across the different areas of functioning is clear. However, when change scores on each subscale are averaged over large heterogeneous groups of clients they appear much smaller because a sizeable proportion of participants score at ceiling to begin with, with the consequence that their change scores must be close to zero. Average or median change scores thus do not give a meaningful picture of the magnitude of gains made by the subgroups of patients to whom the scale was a key indicator of progress.

Therefore, to give as clear as possible a representation of the size and clinical significance of changes made by patients in both the outreach and information groups, an additional "maximum gain index" (MGI) has been computed by identifying for each participant the subscale on which they showed the greatest improvement from intake to follow up; this individually determined change score is the MGI. These data are therefore presented in addition to the more conventional but clinically less easy to interpret total change score (the sum of changes across all six subscales) and individual subscale scores.

\section{Secondary measures}

The functional independence/assessment measure (FIM+FAM)

The FIM + FAM ${ }^{9}$ is a measure of activity (disability) normally used in inpatient settings and scored by a multidisciplinary team. Five of the subscales were used here: personal care (seven items), mobility (seven items), communication (five items), cognition functions (five items), and psychological adjustment (four items). Each of the constituent items in each scale is scored between 1 and 7, and in the present study for ease of comparability subscale scores have been computed by averaging (rather than summing) the scores on the constituent items. Thus scores on each scale can range from 1 to 7 , where in each case a high score represents maximum independence or no disability.

Assessments were conducted in the same way as for the BI. Although reliability has been established in inpatient 
settings, ${ }^{17}$ it remains undetermined in community settings. In practice, some participants could not be scored on the communication, cognitive functions, or psychological adjustment scales, because either their English was poor or there was insufficient time to assess the relevant functions. The reliability of these subscales has been questioned elsewhere. ${ }^{17} 18$

In addition to a total scale score (the sum of scores on the five subscales) and individual subscale scores, MGI was computed in the same way as described above for the BICRO-39 scales.

\section{The hospital anxiety and depression scale (HADS)}

The $\mathrm{HADS}^{19}$ requires respondents to rate the intensity/ frequency over the preceding week of seven symptoms each of anxiety and depression. Maximum score for each mood state is 21 ; scores of 10 or below fall within the normal range. The scales have been extensively validated in healthy and psychiatric populations; ${ }^{19-21}$ they have also been used in neurological population ${ }^{22}{ }^{23}$ but there is no direct evidence of test-retest reliability and sensitivity in these groups. Here, participants completed it only if they had the cognitive and linguistic competence to do so with minimal assistance. Data were thus available at intake and follow up for only 20 outreach and 26 information participants.

\section{Statistical analysis}

For many of the above measures (for example, BICRO-39, FIM+FAM, BI) the distributions were non-normal. Consequently non-parametric statistics (Mann-Whitney $U$ tests) were used to compare the groups on change from baseline to follow up. Change scores were calculated for each variable separately so that in all cases positive scores indicate improvement. All tests were two tailed, although there was a clear directional hypothesis - that is, that the outreach group would improve more than the information group. The correlation between time since injury and change scores was examined within the outreach group, using Spearman's $r$ and two tailed probability tests, for any variable on which an overall effect of outreach treatment was detected.

This study was necessarily exploratory as there are no existing data documenting the magnitude of gains which can be expected in patients with severe brain injury after hospital discharge. Furthermore, the heterogeneous problems presented by this population means that no one scale is sensitive to treatment goals for every client: thus, minimum effect sizes could not be meaningfully specified. Our objective was therefore initially to determine whether or not outreach treatment increased the relative probability and magnitude of improvements. The recruitment target was 40 participants in each group, based on previous findings that the BICRO-39 subscales can detect improvements over a period of rehabilitation in a group of between 10 and 43 clients $^{12}$; this figure was achieved overall, though for reasons described previously, complete data were not available on all measures. There were insufficient clients recruited from either the inpatient unit or the community to conduct separate analyses for these two subgroups.

All analyses were conducted on an intention to treat basis.

\section{RESULTS}

\section{Participant flow and follow up}

A total of 166 patients were referred across the study period; 26 declined to participate in the initial assessment or withdrew before randomisation, and 30 did not meet inclusion criteria. Of the remaining 112 patients, 54 were randomised to outreach and 56 to information.

At follow up, three patients had died, one was in prison, one was untraceable, and 11 either repeatedly failed to attend appointments or refused to participate. In total, therefore, 96 participants (48 outreach, 46 information) were assessed at
Table 1 Characteristics of the outreach and information groups

\begin{tabular}{|c|c|c|}
\hline Variable & $\begin{array}{l}\text { Outreach group } \\
(n=48)\end{array}$ & $\begin{array}{l}\text { Information group } \\
(\mathrm{n}=46)\end{array}$ \\
\hline \multicolumn{3}{|l|}{ Age $(y)$ : } \\
\hline Mean (SD) & $34(11)$ & $35(10)$ \\
\hline Median (range) & $34(17-55)$ & $32(17-63)$ \\
\hline \multicolumn{3}{|l|}{ Sex ratio: } \\
\hline Males: Females & $37: 11$ & $34: 12$ \\
\hline \multicolumn{3}{|l|}{ Years since injury } \\
\hline Mean (SD) & $4.0(4.9)$ & $2.7(3.6)$ \\
\hline Median (range) & $1.3(0.2-20.3)$ & $1.4(0.3-16.4)$ \\
\hline \multicolumn{3}{|l|}{ Source of referral: } \\
\hline Community & 32 & 28 \\
\hline RNRU & 16 & 18 \\
\hline \multicolumn{3}{|l|}{ PTA duration: } \\
\hline$<1$ hour* & 1 & 0 \\
\hline $1-24$ hours & 0 & 0 \\
\hline $1-7$ days & 1 & 4 \\
\hline 7-31 days & 9 & 10 \\
\hline$>1$ month & 37 & 30 \\
\hline & & 2 \\
\hline \multicolumn{3}{|c|}{ Months from allocation to follow up: } \\
\hline Mean (SD) & $25.1(5.3)$ & $24.6(5.6)$ \\
\hline Median (range) & $23.0(18.0-40.0)$ & $23.5(18.0-40.0)$ \\
\hline
\end{tabular}

*For participants with estimated post-traumatic amnesia less than 24 hours, there was other neurological evidence of at least moderate brain injury.

both intake and follow up. Demographic and clinical characteristics of the two groups are shown in table 1 .

The groups were well matched on all variables. Participants were predominantly male and on average in their mid-30s. Median time since injury was 1.37 years but ranged between 3 months and 20 years, with $14.9 \%$ being within 6 months, $41.5 \%$ within a year, and $74.5 \%$ within 4 years. About two thirds of participants were referred from the community. Duration of post-traumatic amnesia (PTA) was estimated retrospectively utilising a structured interview procedure developed by McMillan et al $^{24}$; any days loss of consciousness were included within the total PTA estimate, and where there was evidence of loss of consiousness but participants were unable to provide additional information about the duration of subsequent PTA, duration of loss of consiousness was used to give a conservative estimate of PTA for analysis purposes. However, it proved impossible to make even a conservative estimate for two participants with severe cognitive impairments who were consequently unable to give the necessary information. In these cases, and in the case of one participant who reported no PTA, there was independent medical evidence (neurosurgical evacuation of large subdural haematomas; clear neurological signs) of at least moderate brain damage. Of the remaining 92 participants, these estimates indicated that $99 \%$ had sustained severe brain injury (PTA $>1$ day); indeed, 93\% reported PTA in excess of l week. 53 participants $(58 \%)$ were able to walk unaided at intake; by contrast, most had cognitive difficulties, with only one patient rated as completely unimpaired on the FIM+FAM cognitive functions subscale.

Duration of outreach treatment averaged 28.1 (SD 19.1) weeks. It exceeded a year for six clients, but was complete by 15 months for all but one. Six clients were seen for 6 or fewer weeks, usually either because of changes in their circumstances (for example, moving) or because it proved difficult to engage them in active treatment.

\section{Analysis}

Tables 2-4 show for each measure, for the two groups separately, intake and change scores, and also the numbers and percentages of participants who showed improvement from intake to follow up; the remaining participants showed zero or negative change. 
Table 2 Primary outcome measures: $\mathrm{BI}$ and BICRO-39 intake and change scores (intake minus follow up) and comparison of change scores between groups

\begin{tabular}{|c|c|c|c|c|c|c|}
\hline \multirow[b]{2}{*}{ Scale (No in each group) } & & \multicolumn{2}{|l|}{ Intake scores } & \multicolumn{2}{|l|}{ Change scores } & \multirow[b]{2}{*}{$\mathrm{p}$ Value } \\
\hline & & Outreach & Info & Outreach & Info & \\
\hline $\begin{array}{l}\text { (I) Barthel index } \\
\text { (48 O/R, } 46 \text { info) }\end{array}$ & $\begin{array}{l}\%(n) \text { improving } \\
\text { Median (range) }\end{array}$ & $\overline{20}(6-20)$ & $\overline{20}(4-20)$ & $\begin{array}{l}35.4 \%(17) \\
0.0(-5 \text { to } 5)\end{array}$ & $\begin{array}{l}19.6 \%(9) \\
0.0(-5 \text { to } 4)\end{array}$ & * \\
\hline $\begin{array}{l}\text { (III) BICRO-39 } \\
\text { Total score } \\
\text { ( } 35 \mathrm{O} / \mathrm{R}, 40 \text { info) }\end{array}$ & $\begin{array}{l}\% \text { (n) improving } \\
\text { Median (range) }\end{array}$ & 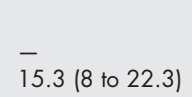 & $\overline{12.9}(8.8$ to 25.7$)$ & $\begin{array}{l}80 \%(28) \\
2.5(-1.7 \text { to } 6.2)\end{array}$ & $\begin{array}{l}70 \%(28) \\
0.9(-4.1 \text { to } 6.8)\end{array}$ & * \\
\hline $\begin{array}{l}\text { Max gain index } \\
\text { ( } 35 \mathrm{O} / \mathrm{R}, 40 \text { info) }\end{array}$ & $\begin{array}{l}\text { Mode } \\
\text { Median (range) }\end{array}$ & $\begin{array}{l}- \\
-\end{array}$ & $\overline{-}$ & $\begin{array}{l}1.5 \\
1.6(0.2 \text { to } 2.6)\end{array}$ & $\begin{array}{l}0.5 \\
1.0(0.0 \text { to } 3.3)\end{array}$ & ** \\
\hline $\begin{array}{l}\text { Subscales } \\
\quad \text { Personal care } \\
\text { ( } 35 \mathrm{O} / \mathrm{R}, 39 \text { info) }\end{array}$ & $\begin{array}{l}\%(n) \text { improving } \\
\text { Median (range) }\end{array}$ & $\overline{0.1}(0$ to 1.8 ) & $\overline{0.0}(0.0$ to 5.0$)$ & $\begin{array}{l}46 \%(16) \\
0.0(-0.3 \text { to } 1.6)\end{array}$ & $\begin{array}{l}26 \%(10) \\
0.0(-1.3 \text { to } 2.7)\end{array}$ & 0.08 \\
\hline $\begin{array}{l}\text { Mobility } \\
\text { ( } 35 \mathrm{O} / \mathrm{R}, 39 \text { info) }\end{array}$ & $\begin{array}{l}\%(n) \text { improving } \\
\text { Median (range) }\end{array}$ & $\overline{2.0}(0.0$ to 5.0$)$ & $\overline{1.7}(0.0$ to 5.0$)$ & $\begin{array}{l}77 \%(27) \\
0.5(-1.4 \text { to } 2.4)\end{array}$ & $\begin{array}{l}62 \%(24) \\
0.4(-2.0 \text { to } 2.5)\end{array}$ & 0.10 \\
\hline $\begin{array}{l}\text { Self organisation } \\
\text { (35 O/R, } 39 \text { info) }\end{array}$ & $\begin{array}{l}\%(n) \text { improving } \\
\text { Median (range) }\end{array}$ & $\overline{2.5}(0.0$ to 5.0$)$ & $\overline{1.5}(0.0$ to 5.0$)$ & $\begin{array}{l}66 \%(23) \\
0.4(-2.8 \text { to } 2.2)\end{array}$ & $\begin{array}{l}45 \%(17) \\
0.1(-1.5 \text { to } 3.1)\end{array}$ & ** \\
\hline $\begin{array}{l}\text { Psychological } \\
\text { (33 O/R, } 40 \text { info) }\end{array}$ & $\begin{array}{l}\%(n) \text { improving } \\
\text { Median (range) }\end{array}$ & $\overline{2.7}(0.5$ to 4.2$)$ & $\overline{2.5}(0.6$ to 4.3$)$ & $\begin{array}{l}68 \%(21) \\
0.6(-2.0 \text { to } 2.6)\end{array}$ & $\begin{array}{l}50 \%(20) \\
0.2(-1.8 \text { to } 1.3)\end{array}$ & * \\
\hline $\begin{array}{l}\text { Socialising } \\
\text { ( } 34 \mathrm{O} / \mathrm{R}, 40 \text { info) }\end{array}$ & $\begin{array}{l}\% \text { (n) improving } \\
\text { Median (range) }\end{array}$ & $\overline{3.6}(1.3$ to 5.0$)$ & $\overline{3.2}(1.6$ to 4.8$)$ & $\begin{array}{l}50 \%(17) \\
0.2(-2.1 \text { to } 2.0)\end{array}$ & $\begin{array}{l}50 \%(20) \\
0.1(-1.2 \text { to } 3.3)\end{array}$ & ns \\
\hline $\begin{array}{l}\text { Employment } \\
\text { ( } 35 \mathrm{O} / \mathrm{R}, 40 \text { info) }\end{array}$ & $\begin{array}{l}\%(n) \text { improving } \\
\text { Median (n) }\end{array}$ & $\overline{5.0}(3.4$ to 5.0$)$ & $\overline{5.0}(2.5$ to 5.0$)$ & $\begin{array}{l}54 \%(18) \\
0.1(-1.6 \text { to } 1.8)\end{array}$ & $\begin{array}{l}45 \%(18) \\
0.0(-1.8 \text { to } 1.3)\end{array}$ & ns \\
\hline
\end{tabular}

\section{Primary outcome measures}

Summary statistics for the BI and BICRO-39 scales are shown in table 2. There were no differences between the groups at intake.

\section{Barthel index}

Sixty per cent of participants scored at ceiling (20) at intake, with a further $14 \%$ scoring 18 or 19 ; consequently, the median change score is zero in both groups. Nevertheless, $35 \%$ of outreach participants showed improvement from intake to follow up, compared with $20 \%$ in the information group. A Mann Whitney $U$ test on the ranked change scores for all participants, including those at ceiling, showed the difference to be significant (mean ranks: information 41.6, outreach 53.2; $U=831, \mathrm{p}<0.05)$.

\section{The BICRO-39 scales}

At intake, $70 \%$ of participants scored within 0.5 points of floor (0: total independence) on independence in personal care and $75 \%$ within $0.5 \%$ of ceiling (5: no activity) on productive employment; the other four subscales showed roughly normal or uniform distributions. All of the following analyses include all participants, regardless of whether they scored at ceiling.

Table 2 shows that total BICRO-39 change score (summed across the six scales) was significantly greater in the outreach group than in the information group (mean ranks: outreach 43.2, information 33.4; $U=517, \mathrm{p}=0.05)$. The MGI correlated highly with total change score $(r=0.72, \mathrm{p}<0.001)$ and showed a similar superiority for the outreach group (mean ranks: outreach 44.3, information 32.5; $U=481, \mathrm{p}<0.05)$. The MGI score distributions, segmenting scores into 0.5 point bandwidths, are shown for the two groups separately in figure $2 \mathrm{~A}$.

It can be seen that the modal change is 1.5 for the outreach group, compared with 0.50 in the information group; median change scores are 1.58 and 1.04 respectively. Maximum possible change on each scale, for someone who moves from total dependence or inactivity to maximum independence or activity, is 6 points; if a clinically significant improvement is defined, somewhat arbitrarily, as a 1.5 point (quarter of the scale) increase, then it can be seen from the figure that this is

Table 3 Maximum gain index: frequencies with which greatest improvement is made on each subscale for BICRO-39 and FIM+FAM separately

\begin{tabular}{llllll}
\hline & \multicolumn{2}{l}{$\begin{array}{l}\text { No with greatest } \\
\text { improvement on each scale }\end{array}$} & & \multicolumn{2}{l}{$\begin{array}{l}\text { No with greatest } \\
\text { improvement on each scale }\end{array}$} \\
\cline { 2 - 3 } BICRO-39 subscales & Outreach & Information & FIM+FAM subscales & Outreach & Information \\
\hline Personal care & 2 & 4 & Personal care & 8 & 4 \\
Mobility & 13 & 7 & Mobility & 2 & 5 \\
Self organisation & 8 & 7 & Cognitive functions & 14 & 8 \\
Socialising & 4 & 9 & Communication & 4 & 8 \\
Psychological well being & 5 & 3 & Psychological & 17 & 18 \\
Productive employment & 3 & 7 & Two or more tied & 3 & 1 \\
Two or more tied & 0 & 3 & & & \\
\hline
\end{tabular}




\begin{tabular}{|c|c|c|c|c|c|c|}
\hline \multirow{2}{*}{$\begin{array}{l}\text { Scale (Nos for two } \\
\text { groups) }\end{array}$} & & \multicolumn{2}{|l|}{ Intake scores } & \multicolumn{2}{|l|}{ Change scores } & \multirow[b]{2}{*}{$\mathrm{p}$ Value } \\
\hline & & Outreach & Info & Outreach & Info & \\
\hline \multicolumn{7}{|l|}{ (I) FIM+FAM: } \\
\hline Total score & $\%$ (n) improving & - & - & $85.4 \%(41)$ & $88.9 \%(40)$ & \\
\hline (48 O/R, 45 info) & Median (range) & 28.4 (6.9 to 34.2 ) & 29.3 (12.0 to 33.7) & $2.8(-2.1$ to 19.1$)$ & $2.5(-1.9$ to 18.9$)$ & NS \\
\hline Max gain index & Mode & - & - & 2.5 & 0.5 & \\
\hline (48 O/R, 45 info) & Median (range) & - & - & $1.6(0.0$ to 5.0$)$ & $1.2(-0.6$ to 3.0$)$ & ** \\
\hline \multicolumn{7}{|l|}{ Subscales } \\
\hline Personal care & $\%(n)$ improving & - & - & $45.8 \%(22)$ & $31.1 \%(14)$ & \\
\hline (48 O/R, 45 info) & Median (range) & $0.1(0$ to 1.8$)$ & $7.0(2.4$ to 7.0$)$ & $0.0(-0.7$ to 3.0$)$ & $0.0(-1.0$ to 1.4$)$ & 0.06 \\
\hline Mobility & $\%(n)$ improving & - & - & $50 \%(24)$ & $48.9 \%(22)$ & \\
\hline (48 O/R, 45 info) & Median (range) & $6.4(1.4$ to 7.0$)$ & $6.6(1.0$ to 7.0$)$ & $0.1(-1.3$ to 2.6$)$ & $0.0(-0.9$ to 2.1$)$ & NS \\
\hline Cognitive & $\%(n)$ improving & - & - & $78.3 \%(36)$ & $68.3 \%(28)$ & \\
\hline (O/R, 41 info) & Median (range) & $4.6(1.2$ to 7.0$)$ & $5.4(3.0$ to 7.0$)$ & $1.1(-0.6$ to 5.0$)$ & $0.6(-1.2$ to 3.0$)$ & 0.09 \\
\hline Communication & $\%$ (n) improving & - & - & $66.7 \%(28)$ & $67.5 \%(27)$ & \\
\hline (O/R, 40 info) & Median (range) & $6.0(2.4$ to 7.0$)$ & $6.1(2.4$ to 7.0$)$ & $0.4(-1.2$ to 4.2$)$ & $0.5(-0.6$ to 1.8$)$ & NS \\
\hline Psychological & $\%(n)$ improving & - & - & $79.2 \%(38)$ & $88.4 \%(38)$ & \\
\hline$(O / R, 43$ info) & Median (range) & $4.6(1.3$ to 6.8$)$ & 4.8 (2.8 to 6.3$)$ & $1.0(-0.3$ to 4.8$)$ & $0.8(0.0$ to 2.8$)$ & NS \\
\hline \multicolumn{7}{|l|}{ (II) HADS: } \\
\hline Anxiety & $\%(n)$ improving & - & - & $50.0 \%(10)$ & $34.6 \%(9)$ & \\
\hline (20 O/R, 26 info) & Mean (sd) & $8.7(4.1)$ & $8.3(4.8)$ & $0.5(4.1)$ & $-0.6(3.8)$ & NS \\
\hline Depression & $\%(n)$ improving & - & - & $50 \%(24)$ & $53.8 \%(14)$ & \\
\hline (20 O/R, 26 info) & Mean (sd) & $7.7(4.2)$ & $8.5(5.0)$ & $0.0(4.2)$ & $0.4(4.0)$ & NS \\
\hline
\end{tabular}

${ }^{* *} \mathrm{p}<0.025$

†Probability levels for group comparisons (two tailed Mann Whitney $U$ tests

achieved or exceeded by $25 / 35$ (71\%) of those receiving outreach treatment compared with $16 / 40(40 \%)$ of those in the information group. A higher success rate in the outreach than in the information group is also seen if the criterion is raised to 2.0 points $(40 \% \vee 20 \%)$ or lowered to 1.0 point $(83 \% v$ $62.5 \%)$.

The percentages of participants making their maximum gain on each of the six subscales is shown in table 3, along with the same information for the FIM+FAM. Thus in the outreach group the scales most likely to detect maximal gain were mobility and self organisation, whereas for the information group the largest gains were most often on socialising. Time since injury was unrelated to the magnitude of gains on these two indices within either the outreach or the information group $(r<0.13$, NS in every case).

With respect to individual subscales, the groups did not differ significantly on either socialising or productive employment, neither of which showed meaningful change in either group. However, outreach participants showed significantly greater gains in self organisation (mean ranks: outreach 43.5, information 32.2; $U=474, \mathrm{p}<0.05$ ) and in psychological wellbeing (mean ranks: outreach 42.8 , information $32.2 ; U=469$, $\mathrm{p}<0.05)$. The outreach group also showed a strong trend towards greater improvement than the information group on mobility (mean ranks: outreach 41.9, information 33.6; $U=529, \mathrm{p}=0.10$ ) and personal care (mean ranks: outreach 41.7, information 33.2; $U=536, p=0.08$ ). To illustrate the impact that the heterogeneity of the sample has on making sense of descriptive statistics for individual subscales, it is interesting to note that although the ceiling effect on personal care at intake meant that the median change on this subscale was zero, $46 \%$ of participants in the outreach group showed at least some improvement compared with only $26 \%$ in the information group.
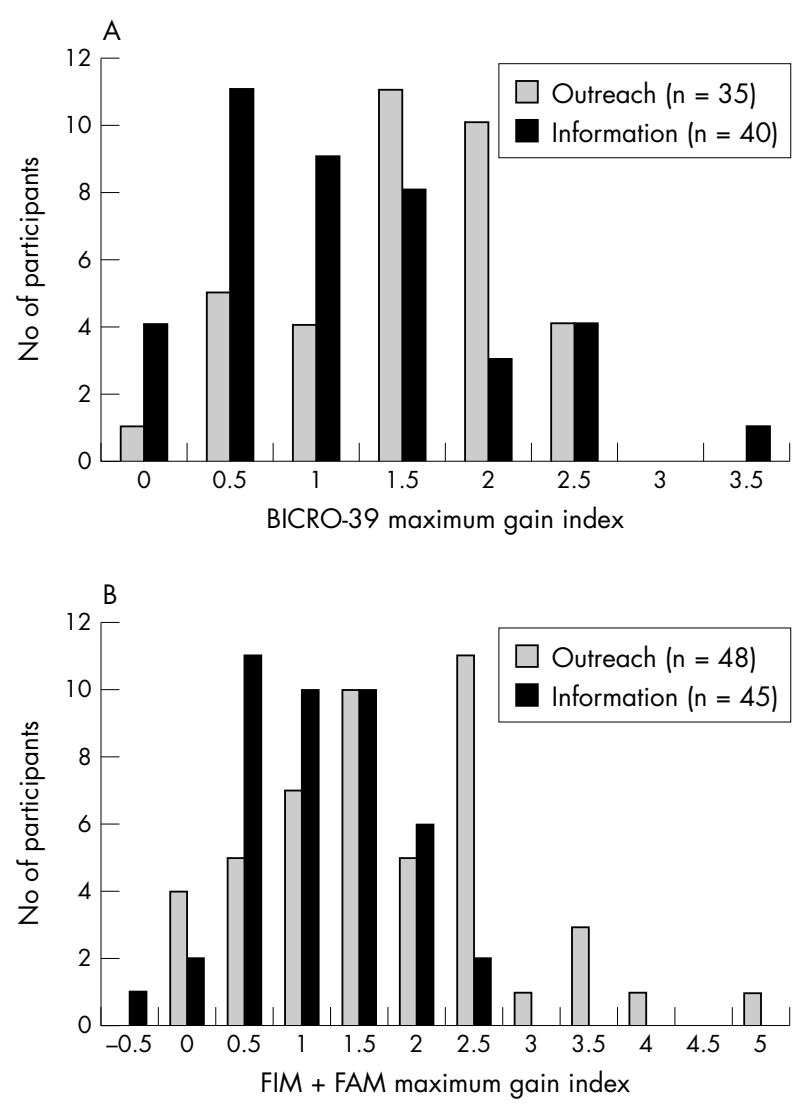

Figure 2 Distribution of $M G I$ for $(A)$ BICRO-39 scales and (B) FIM+FAM. 
There were no significant correlations between time since injury and change on any of the subscales, either in the outreach group or in the information group.

\section{Secondary outcome measures}

Summary statistics for the FIM+FAM and the HADS are shown in table 4.

\section{$\mathrm{FIM+FAM}$}

The personal care, mobility, and communication subscales showed pronounced ceiling effects at intake, with 79\%, 69\%, and 54\% of participants respectively scoring between 6 and 7 (maximum). Psychological adjustment and cognitive functions scores, however, were normally distributed, with only $13 \%$ and $27 \%$ scoring 6 or higher. Again, all analyses include all participants and do not exclude those who score at ceiling. The groups were well matched on all intake scores other than cognitive functions for which the information group showed significant superiority (mean ranks: outreach 51.4, information 38.4; $U=675, \mathrm{p}<0.02$ ).

Total FIM+FAM scores showed a modest and similar improvement in both groups (mean ranks: outreach 46.5, information 47.4; $U=1058.5$, NS). However, the MGI, although highly correlated with change in total score $(r=0.71$, $\mathrm{p}<0.001$ ), was significantly greater in the outreach group (mean rank: outreach 53.2, information 40.4; $U=782$, $\mathrm{p}<0.025)$ : the modal score for outreach participants was 2.5 (median l.6) compared with 0.5 (median 1.2) in the information group. The distribution of MGI scores, segmented into 0.5 point bandwidths, is shown in figure $2 \mathrm{~B}$; it is clear that the peak is shifted to the right in the outreach group. In both groups, more participants showed their maximum gain on the psychological scale than on any other (table 3 ). If a clinically significant change criterion is set at 2.0 points (a third of the maximum 6 points possible), then the success rate for outreach participants is almost double that of the information group ( $46 \% \vee 24 \%)$; a slightly higher criterion of 2.5 points is achieved by three times as many outreach as information participants (35\% $v 11 \%)$; and a slightly lower criterion of 1.5 points is achieved by almost $50 \%$ more outreach than information participants (67\% v 47\%).

Time since injury was uncorrelated with either total or MGI change scores in either the outreach or the information group $(r<0.17$, NS in every case).

On none of the individual subscales did the difference in change scores between the two groups achieve statistical significance, although there was a strong trend for outreach participants to do better than the information group on personal care (mean ranks: outreach 51.8, information 41.9; $U=848$, $\mathrm{p}=0.06$ ) and cognitive functions (mean ranks: outreach 48.3, information 39.1; $U=743, \mathrm{p}=0.09$ ). Despite the ceiling effect at intake for personal care, $46 \%$ of outreach but only $31 \%$ of information participants showed at least a slight improvement from intake to follow up. Interestingly, there was a marginally significant positive correlation within the outreach group between time since injury and improvement in personal care $(r=0.27$, two tailed $\mathrm{p}=0.07)$. By contrast, in the information group the correlation was of similar size but negative $(r=-0.30, \mathrm{p}<0.05)$. There was likewise a trend towards a negative association between time since injury and improvement in cognitive functions in the outreach group $(r=0.24$, $\mathrm{p}=0.10)$, but no association in the information group $(r=0.12$, NS).

\section{HADS scale}

Intake scores were normally distributed, with most participants scoring below clinical cut off values: specifically, $71 \%$ fell into the normal range for anxiety and $65 \%$ for depression, and in both cases only $15 \%$ of participants scored above 13 . The two groups did not differ in the extent of change from intake to follow up for either anxiety or depression.

\section{DISCUSSION}

The present data provide the strongest confirmation to date that structured multidisciplinary rehabilitation delivered in community settings can improve social functioning after severe brain injury. Within this randomised controlled trial, significantly greater gains were made by outreach treated participants than by those given only written information about alternative resources. Improvement with treatment was seen in terms of practical functioning and independence in a range of "normal" activities and also in aspects of psychological wellbeing. Crucially, these improvements were detectable well after outreach treatment finished; thus, gains outlived the period of direct support and motivation provided by therapists.

The indices which demonstrated these effects included both measures of activity and the BICRO-39 scales which were designed specifically to measure community functioning and social participation. Of 18 variables on which the two groups were compared, six showed a significant outreach effect at the 0.05 level of two tailed probability, with four more showing a trend $(\mathrm{p}<0.10)$ in the same direction. Fewer than one out of 20 tests would be expected to reach the 0.05 level of statistical significance by chance; thus it is most unlikely that these findings are spurious. It is particularly interesting that the BI was sensitive to recovery within this sample, as it is widely reported-and indeed was found here- to be limited by a ceiling effect for a high proportion of brain injured patients able to return to their own homes. ${ }^{9}$ Within this study, $60 \%$ of participants scored the maximum of 20 at intake; nevertheless, in the outreach group 35.4\% (most of those with submaximum scores at intake) showed improvement at follow up compared with only $19.6 \%$ of those in the information group. A similar pattern was seen for scores on the FIM+FAM personal care subscale.

Cognitive functions scores from FIM+FAM showed a trend approaching significance towards greater improvement in outreach than information participants. This subscale indexes problem solving, memory, orientation, attention, and safety judgement, all areas of function targeted indirectly by hands on rehabilitation through training clients to increase their independence in organising aspects of their own routine. However, none of the other FIM+FAM subscales detected differential change between the two groups. There are several possible reasons for the lack of effects. Firstly, the functionally oriented approach of the outreach team targeted problem areas reflected in individual items of the communication and psychological adjustment subscales only if they were themselves an obstacle to participation in activities which would otherwise be possible for the individual patient. Secondly, the experience of scoring the FIM+FAM based on the very limited interviews and observation that was possible within one off assessment visits (both at intake and follow up) led to the clinical view that scores were likely to be inaccurate and unreliable; certainly this method of administration departs from the recommended team based approach in the inpatient settings for which the scale was designed, and there is only limited evidence concerning the validity of interview based scoring. This contrasts with the good evidence for the reliability of BIs derived from interview, and both positive and negative FIM+FAM findings should therefore be interpreted cautiously. For further discussion of these and related issues in outcome assessment after brain injury, see Fleminger and Powell..$^{25}$

Total score on the BICRO-39 showed a modest but significantly greater improvement for the outreach than the information group. Of the six subscales, two (self organisation and psychological wellbeing) detected significantly greater gains in the outreach than the information group whereas for a third, personal care, a similar difference between the groups fell only just short of significance $(p=0.08)$. There was a similar trend for mobility $(\mathrm{p}=0.10)$, and when mobility scores 
were analysed for the subgroup of 15 outreach and 14 information participants who showed at least some physical disability at intake (BI scores $\leqslant 19$ ), the outreach group showed significantly greater gains than the information group (median change scores of 1.33 and 0.18 respectively; mean ranks were 18.6 for outreach and 11.1 for information; $U=51.0, \mathrm{p}<0.05)$.

The apparent success of the outreach team in effecting durable gains in these aspects of clients' functioning but not in socialising (frequency of contact with other people outside immediate family) or productive employment (including paid or voluntary work, child care, and education or training) deserves comment. It may be the case that these domains, which involve increased activity outside the home, are more subject to obstacles beyond the direct control of either the client or outreach therapists (for example, accessibility of the environment, availability of opportunities and appropriate adaptations, reactions of other people). Although therapists did focus, often successfully during treatment programmes, on increasing clients' engagement in local leisure and education activities, it seems that clients did not sustain their involvement in these activities or their social contacts once treatment had finished. With respect to return to work, although the team was able to support clients in applying for jobs on the open market and in attempting to return to posts they had held before their accident where these had been left open for them, such opportunities were available to very few clients. The fact that only five participants in the outreach group and eight in the information group were in full or part time paid employment at follow up emphasises the additional need for specialised supported employment programmes for brain injured people such as those described by Buffington and Malec $^{26}$ and Wehman et al. ${ }^{27}$

For psychological wellbeing, although the BICRO-39 detected significantly greater improvement in the outreach group, no differences were found on the HADS anxiety or depression scales. This discrepancy could reflect a lack of power to detect differences within the relatively small sample for whom HADS scores were available (20 outreach, 26 information), although it is notable that participants in both groups were at least as likely to show no change or to decline as they were to show improvements on both anxiety and depression. This is perhaps not surprising as few patients had clinically significant HADS scores at intake; thus, median scores fell well within normal limits. This finding raises the possibility that the greater sensitivity of the BICRO-30 psychological wellbeing scale reflects its item content. These items were derived through factor analysis ${ }^{12}$ of brain injured people's ratings of a much wider range of subjective states, and should thus be particularly sensitive to the experiences of people with brain injury. The symptoms which had the highest factor loadings, and which were retained within the BICRO-39 (anger, impatience with oneself, boredom, loneliness, hopelessness, and feeling overwhelmed/worn out) overlap only partially with those of the HADS. It is easy to see why these are likely to be frequent problems for brain injured people, and encouraging to find that they are amenable to this type of rehabilitation approach. Indeed, $68 \%$ of outreach clients showed at least some improvement on this scale compared with $50 \%$ (close to chance) in the information group.

The possibility of unintentional biases in allocation or subsequent attrition must be considered. Randomisation in the manner described (selection of codes from a sealed envelope) can, like most methods, be distorted if the will is there to do so; and there was a higher rate of attrition from the information than from the outreach group ( $18 \% v 11 \%)$. However, comparison of the participants who were successfully followed up on a total of 22 demographic characteristics and baseline assessment scores, found a difference between the groups on only a single variable (FIM+FAM cognitive functions), in favour of the information group; one significant finding at the 0.05 level of probability is expected in 20 variables by chance alone. It therefore seems improbable that the between group differences in change from intake to follow up has been significantly influenced through allocation or attrition.

The study also attempted to minimise biases on the part of either the assessor or the participants. Thus the outcome assessor was kept blind to treatment condition before her assessment visits, and had no involvement with or investment in the outreach team. She was previously unknown to the participants and introduced the follow up interview in a neutral way. In addition, the BICRO-39 scales were completed by the participants and/or their carers without assistance from the assessor. However, there are two possible sources of bias which could not be excluded. Firstly, although we did not measure the effectiveness of the assessor blinding by asking her to guess group allocations, some clients inadvertently gave information during the interview (for example, mentioning therapists' names) which would have enabled her to guess. However, it is notable that the BICRO-39, the measure which showed the greatest benefit of outreach treatment, was completed by the clients without input from the assessor; thus although we cannot rule out the possibility that her ratings of disability on the BI and the FIM+FAM may have been coloured by expectancies, this does not offer a sufficient explanation for the effects found. Secondly, the participants' own responses may have been biased by their perceptions of the likely value of the treatment condition to which they had been allocated; however, none was receiving ongoing outreach treatment at the time the follow up interview was conducted, and questions all related to present functioning rather than asking for judgements of perceived change over the study period. In considering the extent to which participants' subjective expectancies might contribute to the effects, it is relevant to note that self ratings of anxiety and depression, measures which seem particularly likely to be susceptible to such expectancies, did not differ between the groups.

Unsurprisingly, median change scores on BICRO-39 and FIM+FAM total scale and individual subscales were typically small; this is an unavoidable consequence of the heterogeneity of the problems presented by brain injured patients with complex disability. Thus, no individual scale can be sensitive to the limitations and treatment goals of every patient. Confirming this, most scales showed a substantial proportion of participants scoring at or close to ceiling. Because these participants could not show further improvement, this ceiling effect reduced average or median effects in the group as a whole. Small median change scores therefore do not give a realistic impression of the clinical significance of statistically significant treatment effects as they camouflage potentially huge individual variation.

To examine the issue of clinical significance more directly, we therefore computed for the BICRO 39 and the FIM+FAM separately a maximum gain index (MGI) for each participant, this being the change score on the subscale on which they had shown greatest improvement. For both instruments, the MGI was highly correlated with total scale score, reflecting the fact that the scale of greatest change for the individual participant accounted for the largest part of the change in their total score. The clinical relevance of the MGI lies in the fact that intervention is typically targeted on areas of functioning where there is scope for change rather than on areas in which the patient is already functioning at a high level, or where progress is unlikely because the severity of his or her impairments makes goals in this domain (for example, return to employment) unrealistic. Clearly the areas where there is scope for change are also likely to most prone to spontaneous recovery; however the degree to which this accounts for change shown by outreach clients is taken into account via the comparison with MGI scores computed in the same way for information participants. 
Consideration of the MGIs for the BICRO 39 showed a median increase of 1.58 for the outreach group compared with 1.04 for the information group; the difference is thus just over half a point on a scale which ranges from 0 (total independence or no activity) to 5 (total dependence or inactivity). In terms of the proportions of participants reaching gains which have clinical meaning, more than $83.5 \%$ of outreach clients made a gain of at least 1 point (representing a shift from one response category to the next: for instance, from functioning in a particular domain with "a lot of help" to "some help"). By contrast, only $62.5 \%$ of the information group reached this criterion. The probability of achieving a higher criterion of two points change (for example, a shift from "some help" to "no help") was twice as high for outreach participants than for those in the information group $(40 \% \mathrm{v}$ $20 \%$ ). The domain in which greatest gains were most likely to be made by outreach clients was mobility (13 participants), followed by self organisation (eight); for the information group gains were more evenly distributed across the domains. This pattern, in conjunction with the results of the statistical analyses, suggests that the areas of mobility and self organisation are key targets for outreach rehabilitation, with psychological wellbeing possibly improving as a consequence of increased independence in these areas.

On the FIM + FAM, the relative likelihood of a 2.5 point MGI is even greater for outreach clients: $35 \%$ achieved this level of improvement, which corresponds to a shift of over a third on the seven point scales compared with $11 \%$ of information participants. On this instrument participants in both groups were most likely to show their maximum gains on the psychological scale $(35 \%$ and $41 \%)$, whereas $29 \%$ of outreach clients (compared with $18 \%$ of information participants) showed their maximum gain on cognitive functions.

It is difficult to evaluate cost effectiveness in any simple way; however, the per capita cost of delivering outreach intervention as described earlier (comprising, on average, two sessions a week for 6 months plus associated liaison and administration) was about $£ 6000$. This figure is small in comparison with the acute medical and lifetime care costs arising from severe traumatic brain injury; indeed, in 1995 Brooks et al ${ }^{28}$ estimated the medical costs alone over the first 4 years after injury to be in excess of $£ 100000$ (figure converted from \$US). If the two point criterion change on the BICRO-39 is taken as a clinically meaningful gain-that is, one which represents a marked improvement in a patient's independence and quality of life and which potentially reduces the burden on carers and society, then there may well be longer term savings in future care costs or provision of state benefits to these clients and their families; however, a study with a much longer follow up period would be needed to determine the long term economic impact.

The above figures are in fact likely to underestimate the effectiveness of intervention. Analyses were conducted on the conservative intention to treat basis, including all participants who were randomly allocated even though some in the outreach group in fact received very little input (for example, because they moved away or were ambivalent about the programme); thus, six patients received fewer than 6 weeks of treatment. Conversely, some in the information condition undoubtedly did receive appropriate help from other sources.

Time since injury was either unrelated or, somewhat surprisingly, weakly positively correlated with extent of improvement in outreach treated patients-that is, patients with longer standing injuries tended to make greater gains. This contradicts a common assumption that rehabilitation is only useful if given early. Indeed, we often found that patients who had not received input for many years were well motivated and often responded very well to the provision of relatively simple aids and strategies.

Numerous further questions arise from the present findings. It would be relevant to enquire whether certain sub- groups of brain injured people, defined perhaps on the basis of severity/type of initial impairment or age, benefit more than others from outreach treatment; the present sample size, though larger than that in most rehabilitation trials, is too small to permit meaningful analysis of the impact of these variables. Likewise, there is no apparent reason why this treatment approach should not be equally effective with people whose brain injury is not the result of head trauma; indeed, since the end of the study the outreach team has extended its service to include patients with non-progressive single incident brain injury of any aetiology. Our clinical experience has been that aetiology is much less relevant to treatment success than are psychological and social determinants such as motivation to change and the level of family support. Clinically and economically important questions which must be addressed to guide the future development of services relate to the optimal form or duration of treatment for clients with different types of presenting need. Although the present study does not allow further resolution of these issues, we hope that the encouraging results reported here will provide an impetus for the establishment of more community based teams and for further research into the refinement of approaches to continuing rehabilitation.

\section{ACKNOWLEDGEMENTS}

The research assessor was funded by a grant from the Medical Research Council, and the treatment programme was funded by the Department of Health. We also acknowledge the support provided by Dr Jane McNeil to the research assessor.

\section{Authors' affiliations}

J Powell, J Heslin, Department of Psychology, Goldsmiths College, Lewisham Way, New Cross, London SE 14 6NW, UK

R Greenwood, Regional Neurological Rehabilitation Unit, Homerton Hospital, Homerton Row, London E9 6SR, UK

\section{REFERENCES}

1 Stonnington HH. Editorial: community based rehabilitation. Brain Inj 1997;11:155.

2 Fredrickson $M$, Cannon NL. The role of the physician in the post-acute continuum. Arch Phys Med Rehabil 1995;76(suppl):SC5-9.

3 Willer B, Button J, Rempel R. Residential and home-based postacute rehabilitation of individuals with traumatic brain injury: a case control study. Arch Phys Med Rehabil 1999;80:399-440.

4 Stilwell J, Hawley C, Stilwell P, et al. National traumatic brain injury study: summary of report. Warwick, UK: Centre for Health Services Studies, University of Warwick, 1998.

5 Wade DT, King NS, Wenden FJ, et al. Routine follow up after head injury: a second randomised controlled trial. J Neurol Neurosurg Psychiatry 1998;65:177-83

6 Powell JH. Assessment of rehabilitation outcomes in community/ outreach settings. Neuropsychol Rehabil 1999:9:457-72.

7 Brooks DN.The effectiveness of post-acute rehabilitation. Brain Inj 1991;5:103-9.

8 Mahoney FI, Barthel DW. Functional assessment: the Barthel index. MD Med J 1965;14:61-5

9 Hall KM, Hamilton BB, Gordon WA, et al. Characteristics and comparison of functional assessment indices: disability rating scale, functional independence measure, and functional assessment measure. $J$ Head Trauma Rehabil 1993;8:60-74

10 Hall KM, Mann N, High W, et al. Functional measures after traumatic brain injury: ceiling effects of FIM, FIM+FAM, DRS and CIQ. J Head Trauma Rehabil 1996;11:27-39.

11 Semlyen JK, Hurrell E, Carter S, et al. The Newcastle independence assessment form (research): development of an alternative functional measure. J Neurol Rehabil 1996;10:251-7.

12 Powell JH, Beckers K, Greenwood RJ. Measuring progress and outcome in community rehabilitation after brain injury with a new assessment measure: the BICRO-39 scales. Arch Phys Med Rehabil 1998;79:1213-25

13 Stilwell P, Stilwell J, Hawley C, et al. Measuring outcome in community-based rehabilitation services for people who have suffered traumatic brain injury: the community outcome scale. Clin Rehabil 1998; 12:521-31

14 Collin C, Wade DT, Davis S, et al. The Barthel ADL index: a reliability study. International Disability Studies 1988;10:61-3.

15 Wade DT. Measurement in neurological rehabilitation. Oxford: Oxford University Press, 1992. 
16 Edwards M, Feightner J, Goldsmith $\mathrm{CH}$. Inter-rater reliability of assessments administered by individuals with and without a background in health care. Occupational Therapy Journal of Research 1995:15:103-11.

17 McPherson KM, Pentland B, Cudmore SF, et al. An inter-rater reliability study of the functional assessment measure (FIM+FAM). Disabil Rehabil 1996;18:341-7.

18 Alcott D, Dixon K, Swann R. The reliability of the items of the functional assessment measure (FAM): differences in abstractness between FAM items. Disabil Rehabil 1997;19:355-8.

19 Zigmond AS, Snaith RP. The hospital anxiety and depression scale. Acta Psychol Scand 1983:67:361-70.

20 Spinhoven P, Ormel J, Sloekers PP, et al. A validation study of the hospital anxiety and depression scale (HADS) in different groups of Dutch subjects. Psychol Med 1997;27:363-70.

21 Herrmann C. International experiences with the hospital anxiety and depression scale: a review of validation data and clinical results. J Psychosom Res 1997;42:17-41.
22 Johnson G, Burvill PW, Anderson CS, et al Screening instruments for depression and anxiety following stroke: experience in the Perth community stroke study. Acta Psychiatr Scand 1995;91:252-7.

23 Sutcliffe LM, Lincoln NB. The assessment of depression in aphasic stroke patients: the development of the stroke aphasic depression questionnaire. Clin Rehabil 1998;12:506-13.

24 McMillan TM, Jongen EL, Greenwood RJ. Assessment of post-traumatic amnesia following severe closed head injury: retrospective or prospective? I Neurol Neurosurg Psychiatry 1996;60:422-7.

25 Fleminger S, Powell JH, eds. Evaluation of outcomes in brain injury rehabilitation. Brighton, UK: Psychology Press, 1999.

26 Buffington AL, Malec JF. The vocational rehabilitation continuum: maximising outcomes through bridging the gap from hospital to community-based services. I Head Trauma Rehabil 1997:12:1-1.

27 Wehman PH, Sherron P, Kregel J, et al. Return to work for persons following severe traumatic brain injury: supported employment outcomes after 5 years. Am J Phys Med Rehabil 1993;72:355-63.

28 Brooks CA, Lindstrom J, McCray J, et al. Cost of medical care for a population-based sample of persons surviving traumatic brain injury. $J$ Head Trauma Rehabil 1995;10:1-13.

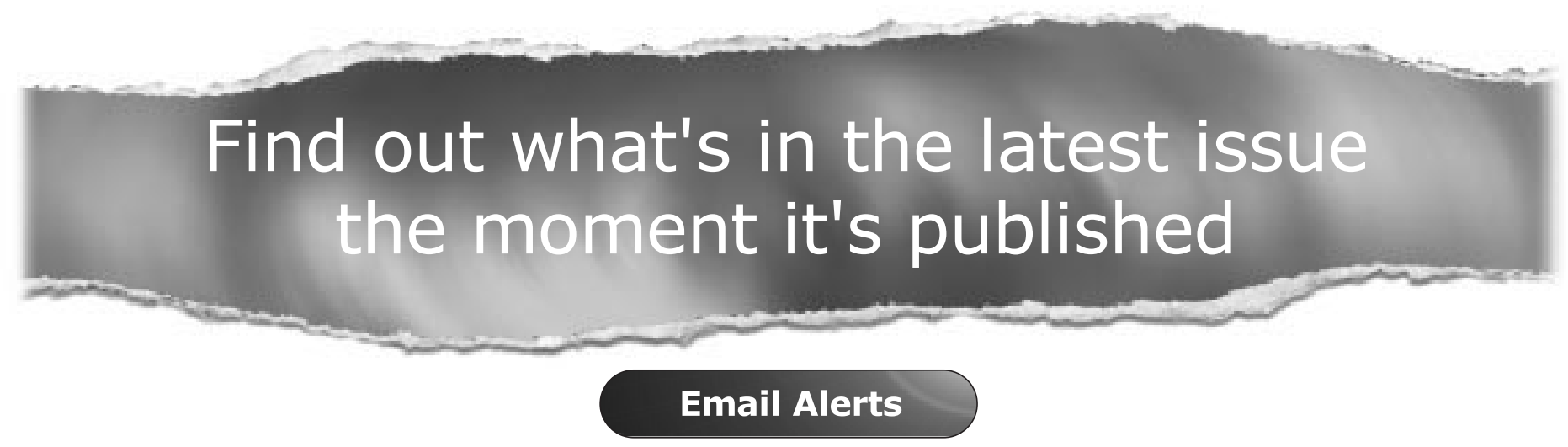

Sign up to receive the table of contents by email every month. You can select from three alerts: Table of Contents (full), TOC Awareness (notice only); Journal of Neurology, Neurosurgery, and Psychiatry related announcements. 